\title{
A Psicologia Social nos Tempos de S. Freud
}

\author{
Gustavo Adolfo Ramos Mello Neto ${ }^{1}$ \\ Universidade Estadual de Maringá
}

\begin{abstract}
RESUMO - Trata-se de uma revisão dos textos psicossociais citados por Freud em Psicologia de massas e análise do eu. O objetivo é propor ao leitor algum conhecimento desses textos que já se perdem no tempo. São referidos textos de Wilfred Trotter, William MacDougall, Gustave Le Bon e Gabriel Tarde. Alude-se também a Durkheim, autor não citado por Freud, mas cuja referência permite contrastar uma visão psicologizante do fenômeno social, que é a de Freud e dos autores que ele cita, com um aporte em que o social é visto como independente do psicológico.
\end{abstract}

Palavras-chave - história da psicologia social; psicologia social; história da psicologia

\section{Social Psychology in S. Freud's Time}

\begin{abstract}
This is a review of the psychosocial texts mentioned by Freud in his Group Psychology and analysis of the Ego. Its aim is to propose to the reader some knowledge of those texts that get lost in the time. Texts of Wilfred Trotter, William MacDougall, Gustave Le Bon and Gabriel Tarde are referred. Durkheim is also alluded, although he is not referred by Freud, but that reference allows to contrast a psychologically centered vision of the social phenomenon, which is the one of Freud and of the authors mentioned by him with a contribution in that the social is seen as independent of the psychological.
\end{abstract}

Key-words - history of social psychology; social psychology; history of psychology.

Há um certo tempo tomei Psicologia de massas e análise do eu, de S. Freud, como objeto de longo trabalho de pesquisa. Tratava-se de uma espécie de leitura livre, em que esse texto freudiano era, sobretudo, contextualizado frente à obra anterior e posterior do autor. Mais que isso, tratou-se de um trabalho "d'explication du texte" (Ramos, 1997). Nos seus preparativos, além da leitura psicanalítica, tive a curiosidade de examinar as referências bibliográficas de natureza social e psicossocial feitas por Freud. Não posso afirmar que esse exame foi de fato surpreendente, mas pareceu-me bem interessante de um ponto de vista histórico, pois tratava-se de livros publicados no início do século $\mathrm{XX}$. Todos juntos pareciam oferecer um curioso panorama do nascimento, sobretudo da Psicologia Social. Tais textos perguntam-se sobre o que é Psicologia, sobre o que é Sociologia, sobre Psicologia Social, sobre se Sociologia é Psicologia aplicada ou, ainda e principalmente, se o fenômeno social tem sua explicação última no psicológico. Eis, pois, uma discussão antiga, mas que é ainda atual. É antiga desde que Durkheim derrotou academicamente Tarde e propôs o fato social como irredutível ao psicológico ou a qualquer outro; e é atual quando, por exemplo, vê-se hoje a obra desse último, sobre a imitação como base da vida social, sendo republicada e reexaminada em contexto acadêmico (Karsenti, 1993).

Pois bem, tendo em vista que o material examinado, devido à sua antigüidade, não é assim tão fácil de ser encontrado; como, também, tive que traduzi-lo do original e

1 Endereço : Rua Prof. Ney Marques, 21. 87020-300 Maringá, PR. Email: garmneto@uem.br como ele nos traz uma discussão historicamente tão pertinente, supus que seria interessante não perdê-lo, mas relatálo, mostrá-lo ao psicólogo e ao psicólogo social através deste artigo. Sendo assim, este último não tem maiores pretensões que expor e comentar trechos dos autores sociais mencionados por Freud em seu Psicologia de massas e análise do eu. Não se trata de analisar o texto freudiano, mas apenas tomá-lo como referência e pretexto para uma, digamos, pintura da discussão em Psicologia Social no princípio do século. É desse modo, pois, que este artigo foge um tanto da referência freudiana e introduz, de maneira a fazer contraste, o pensamento de Émile Durkheim, autor que, de fato, não é citado por Freud. ${ }^{2}$

Comenta-se, neste artigo, além de Durkheim, William MacDougall; Wilfred Trotter; Gustave Le Bon e Gabriel Tarde. Evidentemente, não se trata de discutir toda obra de cada autor, mas os pontos teóricos essenciais, onde os autores definem o campo disciplinar dos seus trabalhos ou onde expõem seus pontos de vista acerca da natureza do social em oposição ou não do individual. É preciso também indicar que o texto de Freud, Psicologia de massas $e$ análise do eu, em si mesmo, não será aqui exposto, embora seja comentado em uma ou outra nota. Para isso, tomo a liberdade de convidar o leitor ao exame de meu outro trabalho (Ramos, 1997).

2 Não em Psicologia de massas e análise do eu. Contudo, em Totem e tabu (1912-1913), iremos encontrar uma referência a Durkheim. Não se trata de discorrer sobre o social propriamente, mas sobre o totemismo. Mesmo assim, tem-se de importante o fato da contemporaneidade entre os autores e o fato de não se desconhecerem inteiramente. 


\section{Os Autores}

\section{William MacDougall}

Em geral, os textos iniciam-se definindo o campo disciplinar de que tratam e em que se inserem: Psicologia Social, Psicologia de Massas; group mind etc.. Entretanto, é interessante notar que não há nesse momento as diferenciações que conhecemos hoje. A diferenciação entre psicologia coletiva (ou de massas), psicologia dos grupos e psicologia social, no princípio do século, não é nada evidente. Introduzindo o assunto dos grupos (groups), MacDougall (1920) relata ter hesitado ao escolher o nome de seu livro. Essa hesitação estava ligada diretamente aos problemas conceituais e de limitação do campo de tais disciplinas. Diz o autor:

Escolhi o título, A mente de grupo (The group mind), após alguma hesitação em favor da alternativa Psicologia Coletiva. Essa última tem a vantagem de já ter sido usada por vários autores continentais, especialmente psicólogos franceses e italianos. Mas, o título que escolhi, penso, é mais distintivamente inglês em qualidade e denota mais claramente o tópico que desejo discutir. (Mac Dougall, p. 1)

Além do problema da escolha de um termo "bem britânico", há outras alternativas e uma diferenciação conceitual. Trata-se da Psicologia Social. MacDougall (1920) contanos, ainda, que havia pensado no título Um esboço de Psicologia Social (An outline of Social Psychology); contudo, duas razões teriam-no impedido. A primeira teria sido a de prevenir-se contra possíveis confusões com o seu livro anterior, conhecido como "Psicologia Social". A segunda razão teria sido a diferença que o autor postula entre Psicologia Social e "Mente dos Grupos":

Concebo a Psicologia dos Grupos como sendo apenas uma parte, embora bem extensa, do campo total da Psicologia Social; pois, enquanto a primeira lida com a vida dos grupos, a última descreve e explica a influência do grupo no desenvolvimento e nas atividades do indivíduo. (Mac Dougall, 1920, p. 2)

Desse modo, de acordo com um dos seus fundadores, a Psicologia Social seria então mais inclusiva e seria também a parte mais "concreta" da própria Psicologia.

\section{Wilfred Trotter}

Entretanto, tais conceitos não são tão unívocos na época. Wilfred Trotter (1919/1953), outro dos autores citados por Freud, mostra-nos essa terminologia de uma outra maneira.

Segundo esse autor britânico, a própria Sociologia não seria outra coisa além de um nome para a Psicologia, uma psicologia, em sentido amplo, capaz de incluir todos os fenômenos do espírito, inclusive os mais complexos. E, além disso, diz Trotter (1919/1953), tratar-se-ia de uma psicologia prática "em um sentido mais completo que aqueles or- todoxos que até aqui têm aparecido" (Trotter, 1919/1953, p. 1). Dessa maneira, segundo Trotter, a Sociologia seria também chamada freqüentemente psicologia social, não diferindo da psicologia ordinária senão porque ela, a psicologia social, concerniria a atividades mentais que aquela, a psicologia ordinária, não poderia abordar por estar relacionada especialmente ao indivíduo. Todavia, segundo esse mesmo autor, isso ainda seria uma afirmação falaciosa, pois

Os dois campos - o social e o individual - são vistos aqui como absolutamente contínuos; toda a psicologia humana, isso é afirmado, deve ser psicologia do homem associado, visto que o homem como animal solitário é algo desconhecido para nós e todo indivíduo deve apresentar as reações características do animal social. (Trotter, 1919/1953, p. 2)

A única diferença entre as duas ciências - a Psicologia e a Sociologia - seria, pois que a Sociologia mostrar-se-ia ligada à vida cotidiana, a vida social. A Sociologia seria psicologia e "seria melhor chamá-la psicologia prática ou aplicada que psicologia social" (Trotter, 1919/1953, p. 2). A ligação entre vida mental social e vida mental individual, Trotter irá encontrá-la no conceito de "social", que por ele é feito equivalente à instinto de rebanho" (herd instinct).

Partindo da afirmação, feita por William James, de que o impulso de um instinto revela-se à introspecção na forma de uma proposição axiomática, Trotter (1919/1953) afirma que o volume de opiniões que temos - representações baseadas nesse caráter é demasiadamente vasta para se enquadrar no dito "triunfo materialista" da época. Ou seja, "descobre-se" que o homem não é movido por algo como uma alma, mas por uma categoria perfeitamente inteligível de um ponto de vista materialista, que é o instinto. A referência a James é interessante e toma o instinto como uma categoria que se revela axiomática, isto é, talvez trate-se aí de uma forma lógico-filosófica de afirmar que o instinto aparece à consciência como uma proposição não só que não necessita demonstração, mas que tem forma imperativa, coagindo o sujeito à ação. Até então ter-se-ia pensado em três tipos fundamentais de instinto: autopreservação, nutrição e sexo. Contudo, para Trotter, isso seria insuficiente, pois, além de tudo, o homem muitas vezes se comporta ao inverso: não se preservando, não se nutrindo e sendo resistente à estimulação sexual. Assim, segundo esse autor, haveria necessidade de pensar em um outro impulso. Um instinto capaz de modificar os outros ao se misturar com eles. Tratar-se-ia de um quarto instinto, cuja significação biológica repousaria no desenvolvimento do gregarismo, isto é, no desenvolvimento de uma vida em comum, que poderíamos já encontrar entre as células dos organismos pluricelulares mais primitivos. Sabemos bem que Freud participa desse mesmo entusiasmo materialista e biologizante. Da mesma forma, sabemos que Freud propõe o modelo da neurose como modelo dessa "desobediência" dos instintos, de que fala Trotter. É o que vemos, por exemplo, no elogio feito a Trotter: "Se damo-nos, então, por objetivo dotar a massa dos atributos do indivíduo, lembramo-nos da anotação substancial de W. Trotter, que vê na tendência à 
formação em massa um prolongamento biológico da multicelularidade de todos os organismos superiores" (Freud, 1921/1991).

Esse quarto instinto proposto por Trotter (herd instinct, instinto gregário), justificar-se-ia em termos darwinistas como uma espécie de aquisição pela qual os organismos complexos tornar-se-iam mais resistentes ao rigor da seleção natural. A explicação de tal hipótese seria fundada na suposição de que a variabilidade das unidades (células) teria, através da união e extensão pluricelular, um limite mais largo, de maneira que os riscos corridos por cada uma, em relação ao ambiente, não comprometeriam o organismo como um todo. O gregarismo seria uma espécie de qualidade fundamental no homem que teria repercussões em sua estrutura mental. A esse propósito, Trotter traz-nos uma discussão com outros autores, que nos parece muito interessante no sentido de conhecer um pouco mais do contexto das reflexões científicas nas quais, de algum modo, Freud mergulha.

Segundo Trotter (1919/1953), um dos raros autores que teria apontado a importância do gregarismo teria sido Karl Pearson ${ }^{3}$. Esse ultimo chamaria a atenção para as mudanças da ação da seleção natural sobre o indivíduo quando esse está em um grupo. Dessa forma, Pearson teria relacionado o que Huxley ${ }^{4}$ chamou processos éticos - o altruísmo - ao gregarismo. Um outro autor discutido por Trotter é o sociólogo americano Lester Ward. Para este último, o que ele mesmo denomina "instinto social ou instinto de segurança da raça" (p. 12) estaria associado ao desenvolvimento do conhecimento racional e poderia ser caracterizado como religião. Mas, isso no sentido de um "plasma indiferenciado do que subseqüentemente se desenvolveu como a mais importante das instituições humanas" (p. 12, tradução minha) $)^{5}$. É interessante notar que Ward duvida se tratase de um instinto ou de algo humano, mas homólogo ao instinto no animal ${ }^{6}$.

Finalmente, um outro pesquisador mencionado por Trotter (1919/1953) é Boris Sidis ${ }^{7}$. Segundo esse último, no psiquismo normal, existiria um "subconscious self", cujas características principais seriam a irracionalidade, a imitação, a credulidade, a covardia e a crueldade. Tal personalidade tão primitiva ocuparia o lugar da personalidade normal, seja durante a hipnose, seja quando o indivíduo passa

3 Socialism and Natural Selection, cit. p. Trotter, op. cit., p. 12.

4 Trotter refere-se provavelmente ao biólogo Thomas Henry Huxley (1825-1895), autor de Evolution and Ethics, de 1893, que foi um dos primeiros defensores da teoria de Charles Darwin na Inglaterra.

5 Lester Ward, Pure Sociology; a Treatise on the Origin and Spontaneous Development of Society, cit. p. Trotter, op. cit, p.12.

6 Isso nos levaria à mais atual das discussões sobre o conceito de pulsão em psicanálise: pulsão versus instinto. Laplanche e Pontalis (1988) em seu Vocabulário da psicanálise preferem traduzir a palavra Trieb, utilizada por Freud como pulsão e não como instinto, como classicamente se fez. Isso ocorre porque "pulsão" traria apenas o sentido de impulso e não de algo pré-fixado como o instinto nos animais.

7 Citado por Trotter, op. cit., p. 14. É importante também relatar que Freud faz uma rápida menção a esse autor em Psicologia de massas e análise do eu, p 57. a fazer parte de uma massa ou multidão. Esse "self" seria responsável pela sensibilidade do homem à sugestão e essa última, por sua vez, seria a responsável pela socialidade humana. Vê-se aí algo que nos lembra Le Bon e Tarde. Entretanto, Trotter (1919/1953) assinala que a existência desse "subconscious self" não é evidente e a sociabilidade humana aparece nessa teoria como resultado de uma desagregação mental, ao inverso de uma qualidade do psiquismo normal. Para Trotter (1919/1953), ao contrário, “o caráter mental gregário é evidente no comportamento humano, não só nas multidões (crowds) e outras circunstâncias de associação atual, mas também em seu comportamento como indivíduo isolado" e "a sugestibilidade humana não é o fenômeno anormal casual que freqüentemente se supõe que seja, mas um instinto normal presente em todo indivíduo", (Trotter, 1919/1953, p. 25), o instinto gregário ou social. Para Trotter (1919/1953) não existe, então, uma cisão capaz de produzir duas "psicologias", uma social ou coletiva e outra individual. Ao mesmo tempo, o "rebanho", como um resultado evolutivo, em um sentido darwinista, seria o único meio pelo qual o espírito humano poderia funcionar de forma suficiente. É aí, na vida social, que o indivíduo encontra as suas próprias opiniões, suas crenças, seus julgamentos, seu poder e, indiretamente, a sua própria consciência. É, assim, nesse sentido que se pode interpretar a recusa de Trotter da expressão "psicologia social”, como uma psicologia especial, uma recusa da idéia de duas essências do funcionamento mental.

A posição do já mencionado MacDougall (1920) é aparentemente diversa e essa suposta divergência coloca-se justamente nesse ponto, o das duas psicologias. Esse autor propõe, de fato, uma psicologia coletiva ou group mind, como já vimos. Seu ponto de partida encontra-se no "sóciodarwinismo" de Herbert Spencer e, do mesmo modo que em Trotter, há em seu texto um elogio da pesquisa do social através da explicação psicológica. Entretanto, MacDougall (1920) não concorda com as idéias spencerianas acerca das relações todo-parte, segundo as quais o todo resulta das qualidades das partes, de maneira que a sociedade seria determinada pelas propriedades dos indivíduos que a compõe. Para esse autor, é evidente que o indivíduo, quando entra em um group, mostra um comportamento que ele não teria mostrado até esse momento, comportamento que se torna latente ou potencial quando o indivíduo deixa de compor o grupo. Assim, MacDougall fala de uma vida mental coletiva que não se explica por uma adição da vida mental de cada indivíduo e a tarefa, que segundo o autor, da "Psicologia dos Grupos" seria, pois, de mostrar os princípios dessa vida mental não individual e irredutível ao indivíduo. Uma tarefa, contudo, que, para ele, aparece como disputada por uma outra ciência: a Sociologia. Todavia, o autor postula que esta última seria um conhecimento muito mais inclusivo que a "Psicologia dos Grupos" e, assim, algo diferente de uma psicologia:

Não desejo reivindicar para a Psicologia dos Grupos o domínio inteiro da Sociologia. Tal como o concebo, tal domínio é 
muito mais amplo que o da Psicologia dos Grupos. A Sociologia é uma ciência que tem uma visão muito mais inclusiva e sintética da vida da espécie humana e tem de aceitar e fazer uso de conclusões de muitas outras ciências, entre as quais a psicologia, e especialmente a Psicologia de Grupos, é muito importante. (MacDougall, 1920, p. 8)

Entre essas ciências estariam também a Climatologia, a Epidemiologia, a Fisiologia e a Genética.

O objeto da "Psicologia dos Grupos" seria, pois, os grupos ou mesmo a sociedade, vista como grupo, mas enfocados como sistemas mentais organizados, cujas estruturas seriam fortemente independentes das qualidades dos indivíduo. Um sistema ou estrutura - de forças mentais - que, embora tenha uma existência independente e anterior ao indivíduo, não teria uma existência externa ao psiquismo individual independente, mas não externo. Tal estrutura mental seria um todo, teria suas próprias leis e seria absolutamente diferente de "atividade mental", pois essa última poderia por vezes se manifestar como consciência, o que a estrutura mental não poderia. É possível, então, que MacDougall atribua o fenômeno da consciência inteiramente ao indivíduo, visto que, no que tange ao grupo, o autor fala-nos de estruturas de forças mentais e não de uma consciência coletiva, conceito que ele rejeita integralmente. Dessa forma, é difícil dizer que em MacDougall a formação coletiva seja comparável à uma espécie de eu individual.

Todavia, não obstante essa diferenciação feita entre "Psicologia dos Grupos" e a Sociologia e malgrado o recorte que distingue a primeira da segunda, de maneira que o estudo das forças mentais fica pertencendo exclusivamente à primeira, podemos encontrar na mesma época, em Durkheim, uma definição do objeto da Sociologia muito semelhante àquele que MacDougall atribui à "Psicologia dos Grupos".

\section{Émile Durkheim}

Durkheim (1974) não é citado por Freud em Psicologia de Massas e análise do eu, contudo, pela importância de sua definição de fato social e pela época de sua produção ser mais ou menos a mesma que a dos autores citados, vale a pena trazer algumas de suas proposições. Diz o autor francês, em 1898:

Se pode-se dizer, à certos propósitos, que as representações coletivas são exteriores às consciências individuais, é que elas não derivam dos indivíduos tomados isoladamente, mas de sua participação; o que é bem diferente. Sem dúvida, na elaboração do resultado comum, cada um traz a sua quota, mas os sentimentos privados só se tornam sociais ao se combinar sob a ação de forças sui generis que desenvolve a associação; como resultado dessas combinações e das alterações mútuas que dela resultam, eles tornam-se outra coisa. (Durkheim, 1898/1974, p. 40)

Ou ainda:

Ora, quando dissemos em outro lugar que os fatos sociais são, em um certo sentido, independentes dos indivíduos e ex- teriores às consciências individuais, não fizemos mais que afirmar do reino social o que acabamos de estabelecer à propósito do reino psíquico [que o estado psíquico não é inerente à célula]. A sociedade tem como substrato o conjunto de indivíduos associados. O sistema que eles formam ao se unir e que varia segundo sua disposição sobre a superficie do território, a natureza e o número de vias de comunicação, constitui a base sobre a qual se eleva a vida social. As representações que são a sua trama liberam-se das relações que se estabelecem entre os indivíduos assim combinados ou entre os grupos secundários que se intercalam entre o indivíduo e a sociedade total. Ora, se não se vê nada de extraordinário em que as representações individuais, produzidas pelas reações trocadas entre os elementos nervosos, não sejam inerentes a esses elementos, o que há de surpreendente em que as representações coletivas, produzidas pela ação e as reações trocadas entre as consciências elementares de que é feita a sociedade, não derivem diretamente dessas últimas e, em consequência, lhes ultrapassam? [...] todos os fenômenos sociais, sem exceção, se impõem de fora ao indivíduo [...]. (Durkheim, 1898/1974, p. 89)

A citação de Durkheim, aqui serve para mostrar por contraste toda a tendência psicologizante dos autores citados por Freud. Contudo, se, de um lado isso questiona o psicologismo, toda redução talvez indevida do social ao psicológico, que estamos vendo até então, em Trotter e MacDougall, não se pode deixar de ver certa semelhança entre Durkheim e MacDougall. A semelhança parece estar em que para esse autor britânico não é possível reduzir a psicologia de grupos à psicologia individual. Mais que isso, essa psicologia de grupos, esse group mind, seria algo que não produz consciência em si mesmo, visto que não é, segundo a linguagem do autor, atividade mental, mas estrutura mental. e de algum modo, então, a group mind de MacDougall faria lembrar a representação (coletiva) de Durkheim (1895/1968). Não se pode esquecer que representação é fenômeno mental, mas é também o elemento do fato social e fato social, para esse autor, não é fenômeno psicológico. Entretanto, são semelhanças superficiais. Não devemos nos apressar em fazer equivaler pensamentos tão distantes...

Então, até aqui, temos como contexto psicossocial de Psicologia de massas e análise do eu, antes de mais nada um ambiente inteiramente darwinista e genético - com exceção de Durkheim, que nem mesmo é citado por Freud, já vimos, mas como contraponto - onde os fatos são vistos como resultado da evolução de outras formas menos evoluídas. Também, do mesmo modo que os organismos são estudados em relação ao ambiente físico, a vida social surge sob a forma de um ambiente possível. Contudo, sua gênese, a relação entre as suas partes e a definição são problemáticas. De um lado, a vida e as formações sociais são vistas como adição, como um meio circundante que se confunde com os próprios indivíduos, como uma expressão de sua própria natureza desenvolvida. Desse ponto de vista, o fenômeno social é conduzido à uma explicação psicológica imediata, de maneira que o meio social, ao responder às necessidades do indivíduo, não pode ter outra natureza se- 
não a deste último. Ou ainda, é o mesmo movimento evolutivo que impulsiona ambos, indivíduo e formação coletiva. É o que se pode encontrar em Trotter e que o conduz a negar a Psicologia Social e a Sociologia. De um outro ponto de vista, os processos evolutivos individuais, sem deixar de serem psicológicos, encontram-se em uma situação de ruptura com o indivíduo, em situação de ser outra coisa diferente dele, como vemos em MacDougall. Tratase de um momento onde a natureza dos fenômenos tornase discutível, pois ao mesmo tempo em que o fenômeno social é algo diferente do individual, mesmo assim, continua a ser fenômeno psicológico. Desse modo, o ser coletivo não é de forma alguma diferente do ser psíquico do homem, mas a sua psicologia se constrói em um outro plano, um plano "estrutural", em MacDougall, independente do indivíduo. De forma diferente, a solução encontrada por Durkheim é de tomar tal exterioridade e independência como razão de uma ruptura mais profunda entre fenômenos individuais e coletivos, estes últimos são então chamados sociais e não psíquicos.

\section{Gustave Le Bon}

Uma solução semelhante à essa de MacDougall, parece, é a de Gustave Le Bon, autor abundantemente citado por Freud e, mesmo por Trotter e pelo próprio MacDougall. É difícil dizer que é Le Bon (1895/1995), em Psychologie des foules, quem criou a idéia de uma profunda cisão entre o fenômeno individual e uma psicologia coletiva. Entretanto, ele a favorece bastante. $\mathrm{O}$ impulso dado por esse autor à tal idéia não nos leva, contudo, como em Durkheim, a uma distinção entre as naturezas desses dois fenômenos (psíquico e social), pois Le Bon fala em "duas psicologias". Contudo, a psicologia das multidões (foules) e a do indivíduo, para esse autor, aparecem postas em relação como que por um abismo.

$\mathrm{O}$ autor não escreve uma obra dedicada ao que hoje conhecemos por Psicologia Social - essa expressão não é utilizada jamais em seu texto -, mas propõe e apresenta como imperiosa uma psicologia das multidões. Essa urgência aparece ligada à uma motivação bastante clara: até aqui, diz Le Bon, "as civilizações foram criadas e guiadas por uma pequena aristocracia intelectual, jamais pelas multidões. Essas últimas não têm potência senão para destruir “ (1895/1995, p. 4). De forma que, "O conhecimento da psicologia das multidões constitui o recurso do homem de Estado que quer, não as governar - isso se tornou hoje muito difícil - mas ao menos não ser excessivamente governado por elas" (p. 5 ).

Tal poder crescente das multidões iria até o ponto de, a cada vez mais, regular a política de maneira que

É um fenômeno bastante curioso ver nos nossos dias papas, reis e imperadores se submeterem ao mecanismo da entrevista, para expor seus pensamentos sobre um assunto dado ao julgamento das multidões. Outrora, pode-se dizer que a política não era coisa sentimental. Poder-se-ia dizê-lo atualmen- te, ainda, ao vê-la tomar como guia os impulsos da multidões instáveis que ignoram a razão, dirigidas somente pelos sentimentos? (Le Bon, 1895/1995, p. 88-89)

Vê-se aí a crescente modernidade dessas afirmações...

Esse ângulo psicológico, digamos, a partir do qual Le Bon encara a política, vai no mesmo sentido de questionar a idéia de regulação das instituições pelas leis e dispositivos institucionais:

As experiências mais continuadas não têm conseguido abalar essa temível quimera. Em vão filósofos e historiadores tentaram provar o seu absurdo. Não lhes foi, contudo, difícil mostrar que as instituições são filhas das idéias, dos sentimentos e dos costumes e que não se refaz as idéias, os sentimentos e os costumes ao se refazer os códigos. Um povo não escolhe as instituições como bem quer, como não escolhe a cor dos seus olhos ou de seu cabelo. (Le Bon, 1895/1995, p. 48)

Evidentemente, nesse trecho, a idéia de inconsciente tem algum papel, pois os governos e instituições seriam, segundo o autor, produtos da raça, do caráter de um povo fatores determinantes de sua psicologia. O inconsciente, por sua vez, seria formado como o substrato invariável de "influências hereditárias".

Para que a política torne-se psicológica no discurso de Le Bon (1895/1995), é preciso que a multidão ou massa seja apresentada como uma espécie de ser unitário munido de características psíquicas, "ela [a multidão] forma um só ser e se encontra submetida à lei da unidade mental das multidões" (p. 9, grifos do autor; entre colchetes: meus comentários). Dessa forma, ela se constitui em um outro ser, diferente dos seres que a compõem, mas é tão anímica quanto eles. Todavia, para que o novo "ser" seja formado, podemos dizer, os indivíduos tornam-se diferentes deles mesmos, eles perdem as suas faculdades superiores, sua autonomia e se apresentam tendidos sob uma unidade maior: "A personalidade consciente desfalece, os sentimentos e as idéias de todas as unidades [indivíduos] são orientadas na mesma direção. Forma-se uma alma coletiva, transitória sem dúvida, mas apresentando características bem nítidas”. (Le Bon, 1895/1995, p. 9)

A massa, então, e os indivíduos que a compõem - ao perder as suas características superiores -, passa a apresentar as qualidades mais ordinárias, medíocres ou primitivas já encontradas no indivíduo, qualidades regidas pelo inconsciente. Este, para Le Bon, já foi dito, seria constituído por influências hereditárias, que seriam semelhantes em todos os indivíduos pertencentes à uma mesma raça. Ora, a aparição preponderante de tais caracteres teria como causa o desfalecimento da individualidade, ou seja, a transformação do indivíduo em parte (do todo). É, então, formado um novo todo que não é a adição, notemos, dos indivíduos ou de suas características e nem mesmo essas últimas se relacionam entre si e com o todo. Há a relação do indivíduo com a raça, que se manifesta - de forma inconsciente, como substrato - nos dois, indivíduo e multidão. Assim, a multidão torna-se ser psíquico, partilhando sua natureza com o 
indivíduo singular, contudo, no nível psicológico mais baixo possível. Tais qualidades da alma da multidão-raça seriam explicadas por Le Bon (1895/1995) por três fatores: o sentimento de poder "invencível", o contágio mental e a sugestionabilidade. Esses dois últimos, por sua vez, seriam explicados como fenômenos de ordem hipnótica.

\section{Gabriel Tarde}

Pode-se encontrar em Tarde, autor também rapidamente citado por Freud, uma explicação aparentemente similar dos fenômenos sociais. Em Les lois de l'imitation (1888/ 1993), Tarde propõe a Sociologia como uma ciência tal como as ciências naturais, o que não é nada diferente de todos os outros autores que foram citados. $\mathrm{O}$ argumento é a repetição. Segundo Tarde (1888/1993), uma ciência se baseia nas regularidades do fenômeno que ela estuda - a repetição -, muito mais que sobre o acidental. Até então, contudo, em ciências sociais, os sábios não teriam mais que mostrado esse último. Todavia, afirma o autor, na vida social há muito mais similitudes que inovações - ou invenções. Ou seja, haveria muito mais regularidade que fatos inesperados. Desse modo, a vida social poderia ser tomada como objeto de uma ciência quantitativa. E, de mais importante, o autor afirma "toda similitude social tem a imitação como causa". (Tarde, 1888/1993, p. 40)

A imitação, para esse autor, é o elemento fundamental de todas as relações sociais e se define como "uma ação à distância de um espírito sobre outro e de uma ação que consiste em uma reprodução fotográfica de um clichê cerebral pela placa sensível de um outro cérebro" (Tarde, 1888/ 1993, p. viii). Assim, trata-se de propagação, propagação de desejos e crenças, que são os únicos fatos sociais para esse autor. Dessa forma, o fenômeno social seria um continuиm em movimento, formado por fluxos de imitação. Tais fluxos tendem a se encontrar e, nesse encontro, eles podem se combinar, se adaptar ou se excluir, se opor. Desse modo, o "tecido social" seria composto por linhas de fluxos de imitação. Ainda, de um encontro bem sucedido entre essas linhas no indivíduo pode nascer a invenção, a criação. Cada invenção, por sua vez, servirá de modelo para novas correntes imitativas. Se, portanto, o elemento social é a imitação, sua origem está na invenção.

A sociabilidade seria pois imitação e um grupo social, para Tarde (1888/1993), é "uma coleção de seres em situação de se imitar mutuamente" (p.78, ). Essa ação, a ação de imitar, tenderia muito mais à propagação que a organização. Assim, para Tarde, a organização social é algo secundário em relação à propagação, a organização seria antes um meio para tal propagação de fluxos imitativos. Portanto, podemos pensar que o elemento do social não é a tendência a se estruturar, mas a se reproduzir e a espalhar o seu laço. A organização surgirá, assim, para tornar mais efetiva uma tal expansão. É a analogia com os seres vivos. Para Tarde, continuemos, e isso parece ser algo de bem atual, a imitação é um fenômeno social e psicológico ao mesmo tempo. Ela seria um elemento que explica inteira- mente o social, mas ela mesma necessita de explicação e Tarde, tal como Le Bon, a encontra na hipnose. Portanto, se essa última explica a imitação e a imitação os laços na sociedade, o estado social aparece como uma espécie de sonho ou ilusão. Diz o autor: "O estado, como o estado hipnótico, não é mais que uma espécie de sonho, um sonho de comando e um sonho de ação. Ter apenas idéias sugeridas e as crer espontâneas: tal é a ilusão própria ao sonâmbulo e também ao homem social" (Tarde, 1888/1993, p. 84, ). Assim, nós nos cremos autônomos, mas seríamos, de fato, inteiramente comandados. E, ainda, diz o autor, nas sociedades contemporâneas, a influência, a magnetização é mútua entre os indivíduos, mas sua fonte teria, como na hipnose, uma relação mestre-sujeito. Desse modo, nas sociedades antigas, os chefes e profetas teriam tido um papel fundamental. Isso, pois, valeria também para as sociedades modernas, em uma certa medida, pois nós exageraríamos tal mutualidade, por orgulho igualitário, afirma o autor. Ou, mesmo, nessas sociedades modernas, a iniciação social é sempre unilateral, uma vez que ela se passa na família, onde "o pai é e será sempre o primeiro mestre, o primeiro sacerdote, o primeiro modelo do filho. Toda sociedade começa assim" (Tarde, 1888/1993, p. 84,). Temos, assim, a sociedade reduzida a uma relação dual e unilateral onde o mestresenhor reinaria através de seu prestígio. Prestígio de magnetizador, que não necessita mentir ou aterrorizar, mas, sim, de despertar no magnetizado uma "força potencial de crença e desejo" (Tarde, 1888/1993, p. 84, ). Notemos pois que para Tarde não há mais que dois tipos de fatos sociais, as crenças e os desejos, ou seja, as faculdades mais manipuláveis na situação hipnótica. Dessa forma, como para Durkheim (1895/1968), a vida social se constitui de representações e de representações que impulsionam o indivíduo. Mas, se para esse último tais representações são colocadas acima do indivíduo, para Tarde isso não ocorreria visto que a imitação - veículo das representações - se passa entre os indivíduos.

Se o hipnotizador, então, é copiado, mas ele mesmo não copia seu sujeito e dessa forma pode se colocar acima dos outros indivíduos, na vida desperta isso se passa de outra forma. Aí as pessoas exercem, uma sobre a outra, uma espécie de prestígio mútuo. A esse último atribui o nome, criado por Adam Smith, de simpatia. Tarde (1888/1993) afirma, ainda, que a origem da sociedade se baseia sobre o prestígio, a magnetização unilateral, que "deve preceder a recíproca" (p. 85).

\section{Conclusão}

Essa relação unilateral do chefe, do pai, vimos, com o sujeito, que estaria na origem do social, seria algo bem diferente do terror. Isso se passa de um modo que, de fato, faz com que Freud e Tarde se aproximem de algum modo. Trata-se também em Tarde (1888/1993) de uma relação de amor. Os reis-deuses, que estariam no berço da sociedade, seriam antes de tudo amados por seus filhos e escravos, muito mais que ele os amaria. Uma história de amor infeliz: 
O próprio amor filial, pois, teria começado por ser em parte um amor infeliz, debilmente mútuo. Pode-se representar o rei, o juiz, o sacerdote, o instituidor único dos primeiros tempos, como um Luís XIV em versão reduzida; não admitindo nenhum direito de seus sujeitos sobre ele e oferecendo-se como perfeito egoísta à sua adoração, embora ele se colocasse o dever de lhes proteger, com vistas à sua própria glorificação, pelo que, aliás, eles lhe eram reconhecidos, como se se tratasse de um benefício. Daí a sua apoteose, necessária ao culto doméstico e à perpetuação da família, fundamento da cidade e da civilização. (Tarde, 1888/1993, p. 221)

As semelhanças com as propostas de Freud sobre o pai da horda primitiva podem ser aí bem interessantes ${ }^{8} \ldots$

Contudo, o que mais interessa aqui, primeiro, diz respeito a essa polêmica - que está na raiz tanto da Sociologia como da Psicologia Social nascentes - entre a explicação propriamente social do fenômeno coletivo e uma explicação de natureza psicologizante, como se vê em Tarde e, mesmo, em Le Bon. Neste último, temos, ainda, a comparação da formação coletiva com o indivíduo, o que leva a um novo problema. Em ambos, enfim, Tarde e Le Bon, tem-se as idéias de hipnose e de sugestão como explicação psicologizante e última do fenômeno coletivo. É como se a vida social fosse um sonho em estado de sono artificial ou hipnótico. Desse modo, é possível pensar a representação coletiva como muito mais próxima da ilusão e da alucinação do que da percepção e do conceito. Isso diferentemente de Durkheim (1895/1968) que a toma muito mais próxima desse último par'. Na verdade, essas idéias retratam muito bem o horizonte epistêmico de uma Sociologia e de um Psicologia Social e, mesmo, de uma Psicologia de há quase cem anos, portanto nascentes. Trata-se de um horizonte onde palavras como hipnose, sugestão, magnetismo, contágio, alma da raça, vindas do vocabulário médico, irão interagir com conceitos biológicos de herança e de homem primitivo entranhando-se, então, fortemente em todo o discurso que, nesse momento, se pensa científico. Vimos que tanto os textos franceses (Le Bon,1895/1995, e Tarde 1888/1993), como os ingleses (Trotter,1919/1953, e MacDougall, 1920) que, por sinal, são mais recentes que aqueles, conterão essa

8 Bruno Karsenti (1993, p. xiv, n. 17), H. F. Ellenberger, citado por Serge Moscovici (1991, p. 295), e o próprio Moscovici (1991, p. 295) falam de uma notável semelhança entre as idéias de Freud e de Tarde sobre as massas. De fato, Freud recebe as influências de seu tempo. Contudo, essas influências se recompõem, no texto freudiano, de maneira a formar um todo cuja originalidade é difícil de contestar. Daí saltam as diferenças. Podemos afirmar, por exemplo, que essa teoria de Tarde sobre a ascendência do pai e a imitação daí derivada é muito próxima da de Freud somente se esquecermos da sexualidade, da ambivalência de sentimentos e do complexo de Édipo. Não podemos esquecer de que é desses elementos que Freud está falando ao falar do pai, seja a pretexto das massas ou à conta da horda primitiva.

9 E, mais tarde, de Moscovici (1978) que retomará a idéia durkheimiana de representação coletiva através da idéia de representação social. Segundo esse autor, a representação é um processo que torna intercambiáveis percepção e conceito. forma de discurso. Entretanto, é preciso salientar uma diferença bem notável: o texto de origem britânica está fortemente marcado pelo darwinismo, de maneira que sua linguagem evolucionista, sobretudo em Trotter, dirige-se para as idéias de adaptação e seleção natural. Aliás, por isso mesmo, no texto anglo-saxão o evolucionismo parece ser mais sofisticado. De semelhante, enfim, chamo, nova e brevemente, a atenção para a redução do social ao psicológico que se opera tanto no texto britânico, como no texto continental. Entretanto, foi possível apontar nuanças. Vimos que em autores como MacDougall (1920) e Le Bon (1895/1995) o ponto de partida é a expressa recusa em deixar reduzir psicologia social à psicologia individual. Em Trotter (1919/ 1953), ainda, há mesmo uma recusa em aceitar uma psicologia individual como fenômeno realmente observável; para ele a psicologia "prática", isto é, empiricamente observável é a do homem em relação, o que já está abordando o problema atual de se toda psicologia é ou não social. Em Tarde isso parece não ser muito claro. Tem-se, nesse autor, a explicação do fenômeno social por algo de natureza, ao mesmo tempo relacional - só é possível a hipnose e a sugestão entre pelo menos duas pessoas - e individual - ser hipnotizado exige uma potência pessoal para isso. O que explica o social, aí, portanto, parece vir de uma psicologia individual ou, pelo menos dual. Entretanto, há algo de talvez bem atual em Tarde e na sua idéia de fluxos de imitação. A atualidade não está, evidentemente, na idéia de imitação, mas na idéia de fluxos fortemente repetitivos que, por vezes, num encontro feliz, fazem produzir o novo. Temos aí, com Tarde, algo que talvez seja mais que atual e que esteja necessitando de discussão ou, mesmo, de reintrodução em Psicologia e Psicologia Social: é a idéia de fluxo versus organização e estrutura. Vimos que o autor pensa que o elemento do social é mais um reproduzir-se (por fluxos) que um estruturar-se organizativamente. Ora, a introdução das teorias de campo em Psicologia Social por Lewin (1948/1973), por exemplo - extremamente voltada para as idéias de organização e estrutura, talvez tenham nublado um pouco a visão de uma discussão alternativa. Penso que idéias de propagação e fluxo podem trazer algo de novo à pesquisa e à reflexão, especialmente acerca da reflexão sobre a novidade e o repetitivo na vida social.

\section{Referências}

Durkheim, E. (1968). Règles de la Méthode Sociologique. Paris : PUF. (Trabalho originalmente publicado em 1895 ).

Durkheim, E. (1974). Représentations individuelles et represéntations collectives. In: Sociologie et philosophie (p. 38-90), $4^{\circ}$ ed. Paris: PUF. (Trabalho originalmente publicado em 1898).

Freud, S. (1991). Psychologie des masses et analyse du moi. In: Oeuvres complètes (Vol. XVI, p. 1-83). (J. Laplanche e cols., Trads.) Paris : PUF (Trabalho originalmente publicado em 1921).

Karsenti, B. (1993). Présentation. In: Tarde, Les lois de l'imitation (p. vii-xxvi). Paris: Kimé. 
Laplanche, J.; Pontalis, J.B. (1988). Vocabulário da psicanálise. (P. Tamen, Trad.). São Paulo: Martins Fontes. (Trabalho originalmente publicado em 1967).

Le Bon, G. (1995). Psychologie des foules. $5^{\circ}$ ed., Paris, PUF (Trabalho originalmente publicado em 1895).

Lewin, K. (1973). Problemas de dinâmica de grupo. $2^{\text {a }}$ edição. (M. Moreira Leite, Trad.). São Paulo: Cultrix. (Coletânea divulgadora da obra do autor, publicada originalmente nos Estados Unidos em 1948).

MacDougall, W. (1920). The Group Mind. Cambridge: University Press.

Ramos, G.A. (1997). Le social dans la construction freudienne de la psychanalyse. Paris: L'Harmattan.
Moscovici, S. (1978). A representação social da psicanálise. (Á. Cabral, Trad.). Rio de Janeiro: Zahar. (Trabalho originalmente publicado em 1961).

Moscovici, S. (1991). L'âge des foules. Edição refundida. Paris: Complexe. (A primeira edição é de 1981).

Tarde, G. (1993). Les lois de l'imitation. Paris, Kimé. (Trabalho originalmente publicado em 1888).

Trotter, W. (1953). Instincts of the Herd in peace and war. Oxford: University Press. (A primeira edição do texto integral é de 1919. Os dois primeiros ensaios são de 1909).

Recebido em 19.10.1999

Primeira decisão editorial em 23.03.2000

Versão final em 18.04.2000

Aceito em 04.09.2000

\section{INTERESSADO EM AGILIZAR A PUBLICAÇÃO DE SEU ARTIGO?}

\section{Informações e dicas para os autores sobre aspectos operacionais}

\section{O manuscrito é reencaminhado pelo autor em versão reformulada}

A produção gráfica do trabalho é executada através de editoração eletrônica, daí a exigência do exemplar em disquete, além de três exemplares em papel da versão reformulada. Quando a versão reformulada é aceita e são poucos os reparos, as correções necessárias são feitas na secretaria da revista. Com o disquete disponível o processamento pode ser imediatamente iniciado. Na falta de disquete não é possível o processamento de correções nem a preparação do manuscrito para editoração. Em suma, atraso para entrar no prelo.

\section{Informações e dicas para os autores com artigos no prelo}

\section{O manuscrito é encaminhado para editoração}

No caso de o manuscrito ser aceito para publicação, é esperada a participação do autor no processo de preparação do artigo na fase de editoração. A primeira prova do artigo, editada a partir da versão em disquete, é enviada para exame ao(s) autor(es). O prazo para devolução é de 48 horas. A obediência ao prazo permite a manutenção da composição prevista para o volume/número da revista. $\mathrm{O}$ atraso no envio da prova examinada pode implicar em mudanças na composição de um número no prelo. E pode resultar em atraso na edição final. 